\title{
Deve a economia feminista ser pós-colonial? Colonialidade económica, género e epistemologias do Sul
}

Must Feminist Economy be Postcolonial? Economic Coloniality, Gender, and Epistemologies of the South

L'économie féministe doit-elle être postcoloniale? Colonialité économique, genre et épistémologies du Sud

Luciane Lucas dos Santos

\section{OpenEdition}

\section{Journals}

Edição electrónica

URL: http://journals.openedition.org/rccs/6797

DOI: $10.4000 /$ rccs. 6797

ISSN: $2182-7435$

\section{Editora}

Centro de Estudos Sociais da Universidade de Coimbra

Edição impressa

Data de publição: 1 Dezembro 2017

Paginação: 161-186

ISSN: 0254-1106

Refêrencia eletrónica

Luciane Lucas dos Santos, « Deve a economia feminista ser pós-colonial? Colonialidade económica, género e epistemologias do Sul », Revista Crítica de Ciências Sociais [Online], 114 | 2017, colocado online no dia 20 dezembro 2017, criado a 03 maio 2019. URL : http://journals.openedition.org/ rccs/6797; DOl : 10.4000/rccs.6797 


\section{LUCIANE LUCAS DOS SANTOS}

\section{Deve a economia feminista ser pós-colonial? Colonialidade económica, género e epistemologias do Sul*}

Neste artigo analiso o fenómeno da colonialidade económica, observando os seus impactos no tecido social e o modo como atinge particularmente a vida das mulheres - nomeadamente as subalternas, estejam elas nas periferias das grandes cidades do mundo ou constituam minorias numéricas ou simbólicas no Sul ou Norte globais. Interessa-me verificar de que modo as colonialidades económica e de género interagem, acentuando a situação de desigualdade em que se encontram estas mulheres. Por fim, indago em que medida as economias feministas podem vir a dialogar mais estreitamente com as teorias pós-coloniais - em particular os estudos pós-coloniais da Economia - e com as epistemologias do Sul, de modo a expor as contradições do discurso moderno de desenvolvimento. Argumento que as economias feministas podem beneficiar da perspetiva pós-colonial e das epistemologias do Sul para analisar as inconsistências da universalização deste discurso e a dinâmica interseccional que conecta questões de género, raça/etnia e classe no âmbito da Economia.

Palavras-chave: colonialidade económica; Economia Feminista; epistemologias do Sul; estudos pós-coloniais da Economia; género.

\section{Introdução}

Em todo o mundo, empresas, instituições e governos têm reproduzido conceitos pré-fabricados e universalistas de pobreza e riqueza. Estes conceitos constituem uma espécie de régua consensual a partir da qual se analisam populações e economias (Zein-Elabdin e Charusheela, 2004) e se legitimam tecnologias de 'intervenção social'-, sobretudo em relação às mulheres periféricas. Em lugar de uma análise situada e interseccional, o mais comum

\footnotetext{
* Este artigo foi desenvolvido no contexto do projeto internacional "Alice: espelhos estranhos, lições imprevistas", coordenado por Boaventura de Sousa Santos no Centro de Estudos Sociais da Universidade de Coimbra e financiado pelo European Research Council, Sétimo Programa-Quadro de Investigação e Desenvolvimento Tecnológico da União Europeia (FP/2007-2013) / ERC Grant Agreement n. ${ }^{\circ}$ 269807. O texto é resultado do apoio concedido por este projeto.
} 
é que as organizações e os governos optem por uma análise limitada do contexto cultural, sociopolítico e histórico destas mulheres, adotando uma linguagem redutora que assume contornos excessivamente técnicos.

Neste artigo, parto dos estudos pós-coloniais da Economia para argumentar que a colonialidade económica é a ideia pulsante que movimenta esta análise reducionista e repetitiva, com consequências relevantes para as mulheres subalternas, ${ }^{1}$ a começar pela insistência em ignorar a sua heterogeneidade, reunindo-as sob o rótulo vazio de "mulheres do Terceiro Mundo". Ao mesmo tempo, afirmo que a colonialidade económica - que também se alimenta da colonialidade de género (Lugones, 2008) - influencia a perceção social e os debates em que género e desenvolvimento aparecem juntos. Esta redução dos sentidos pode ser identificada de forma particular quando se trata de dar conta das múltiplas corporalidades subalternas e das questões específicas que a economia e o discurso do desenvolvimento trazem para a vida destas diferentes mulheres - mulheres negras e periféricas de comunidades pobres, mulheres indígenas, imigrantes islâmicas, mulheres ciganas, mulheres transgénero, para citar algumas das que estão em situação de explícita vulnerabilidade. Assim, argumento que a colonialidade económica contribui para o velamento da diversidade e da interseccionalidade nas questões de género, bem como para a perpetuação de um imaginário social preso à ficção moderna do desenvolvimento como única forma de organização da vida material. Este imaginário manifesta-se por vezes, no próprio olhar subalterno, confirmando aquilo que Gramsci (1971) identificou como consentimento das classes subalternas e que Gayatri Spivak (1988) denominou, ao lembrar a heterogeneidade destes sujeitos, de "subjetividades precárias”, resultantes de uma violência epistémica continuada.

Por colonialidade económica entendo uma forma de poder sobre o imaginário e a vida material dos grupos subalternos que não só emula um caráter de verdade, escondendo a particularidade dos interesses a que responde, como também se legitima a partir de discursos específicos, calcados num imaginário "evolucionista" de desenvolvimento e, não raro, numa construção "orientalista" (Said, 2007) do Outro. Neste cenário, o sentido de alteridade é estrategicamente 'manuseado', de modo a que as guidelines de desenvolvimento sejam o parâmetro de análise.

\footnotetext{
${ }^{1} \mathrm{O}$ sentido de subalterno empregado neste artigo mantém relação com o conceito inicialmente proposto por Gramsci e, mais adiante, trabalhado pelos autores dos Estudos Subalternos - a saber, Ranajit Guha, Dipesh Chakrabarty, Partha Chatterjee e Gayatri Spivak. A diferença principal entre as duas abordagens reside no facto de que Gramsci não vê hipótese de autonomia imediata para o subalterno - submetido como está ao controle das elites -, enquanto, para os Estudos Subalternos, tal autonomia, ainda que pequena e fragmentada, é reconhecida e funciona como ponto de partida para a construção de uma outra historiografia.
} 
A respeito do conceito de colonialidade económica que aqui emprego, esclareço, ainda, que a perspetiva adotada se distancia um pouco da aceção de Walter Mignolo (Mignolo, He e Xie, 2012) segundo a qual a colonialidade económica pode ser entendida como sinónimo de economia de crescimento ou do capitalismo em si. Argumento que é preciso atenção aos mecanismos específicos e situados através dos quais as categorias encontram sentido (ou não) nos referentes locais. ${ }^{2}$ Dialogo, sim, com a noção de colonialidade proposta pelos teóricos decoloniais (Quijano, 1992a, 2000a; Mignolo, 2000; Lugones, 2008), mas, relativamente à colonialidade económica, busco fonte de inspiração na crítica pós-colonial da Economia (Charusheela e Zein-Elabdin, 2003; Zein-Elabdin e Charusheela, 2004; Graubart, 2004; Danby, 2004; Olmsted, 2004), cujas premissas e pontos de partida não são exatamente os mesmos. ${ }^{3}$

Esta colonialidade económica a que me refiro cria a ficção de um parâmetro universal de comparação, mediante o qual uns estão mais adiantados do que outros - sejam indivíduos, grupos sociais, economias ou grupos translocais. Tal processo naturaliza-se de duas formas: 1) desdobrando-se para outras dimensões da vida, como o contexto das subjetividades, a partir da identificação de economias subalternizadas com parâmetros eurocêntricos de produção e consumo; 2) com o apagamento das "pegadas" do "não-económico" por trás do "económico" (Zein-Elabdin, 2004), desaparecendo com elas as histórias subjacentes à construção de categorias e teorias tomadas como neutras (Graubart, 2004). Cumpre, assim, observar que, além de uma visão mais alargada da Economia, entendida como o campo da provisão e não como sinónimo de mercado - como vários/as autores/as já assinalaram (Caldas, 2010; Ferber e Nelson, 2003), é preciso reconhecer que há uma história e uma perspetiva por trás das categorias e dos modelos e/ou teorias económicas que adotamos, com efeitos concretos sobre países, pessoas e grupos sociais.

\footnotetext{
${ }^{2}$ Pelúcio (2012: 404), a partir de Shohat, lembra-nos que as categorias aparecem "como se [...] existissem ou houvessem existido em todos os lugares e em todos os tempos operando sobre os mesmos referentes". Sem perder de vista que o pensamento decolonial nada tem de maistream, entendo que ele, em certa medida, pode incorrer no mesmo erro: o de tomar certas categorias como universais para análise de diferentes cenários, em nome do modelo do sistema-mundo, ignorando, por vezes, a relação categoria-referente.

${ }^{3}$ As teorias pós-coloniais e decoloniais, embora compartilhem a preocupação com a invisibilidade de outras narrativas sociohistóricas pelo discurso da modernidade ocidental, possuem pontos de partida, referencial teórico e enquadramento temporal diferenciados, como lembra Bhambra (2014). O pensamento pós-colonial, mais próximo dos estudos subalternos, entende a modernidade como uma particularidade, como a construção de uma posição de enunciação (Bhambra, 2014; Chakrabarty, 2007). O movimento decolonial, por sua vez, dialoga com a teoria do sistema-mundo de Wallerstein e apoia-se no par modernidade-colonialidade, reforçando a ideia de que as relações coloniais constituíram a base sobre a qual a própria Europa se consolidou como projeto moderno (Bhambra, 2014).
} 
A linha de reflexão deste artigo não se restringe, entretanto, a uma reflexão conceitual sobre a colonialidade económica. Procuro aqui pensar de que modo esta colonialidade se articula com a questão de género. E procuro evidenciar, em termos teóricos, que a Economia Feminista pode beneficiar de um diálogo com as teorias pós-coloniais e com as epistemologias do Sul (Santos, 2010, 2014). Neste sentido, estruturo o meu argumento em quatro partes. $\mathrm{Na}$ primeira, discuto a colonialidade da Economia - tendo em conta o modo como poder e saber se articulam no âmbito deste campo de conhecimento ora para definir categorias e fundamentar representações, ora para definir os destinos de populações subalternas através da narrativa do desenvolvimento. $\mathrm{Na}$ segunda parte, discuto a importância do conceito de interseccionalidade (Creenshaw, 1991; Brah, 2006; Yuval-Davis, 2011) para uma análise mais apropriada dos dilemas e estratégias adotadas por diferentes grupos de mulheres na reação à escassez de recursos e oportunidades. Observo, aqui, as engrenagens de retroalimentação entre colonialidade económica e colonialidade de género. Na terceira e última secção, parto das economias feministas para indagar sobre a viabilidade, a conformação e os possíveis contributos teóricos de uma economia feminista pós-colonial. Analiso, também, em que medida as economias do Sul, que implicam simultaneamente outras lógicas produtivas, suscitam importantes questionamentos à Economia, seja no âmbito da relação entre o doméstico e o económico, seja na (re)valorização dos princípios económicos de redistribuição e reciprocidade. Partindo do conceito de epistemologias do Sul, de Boaventura de Sousa Santos (2010, 2014), procuro lançar algumas luzes sobre alguns contributos que as economias do Sul, com o protagonismo das mulheres, podem trazer para um alargamento epistemológico e político da Economia e da Economia Feminista.

\section{Da colonialidade económica como modo de perpetuação da subal- ternidade}

A Economia, como campo de conhecimento, é uma construção bastante recente (Mitchell, 2005). Apesar disso, ela tem usufruído da sua prerrogativa científica para se constituir como a 'régua' a partir da qual são compreendidas e avaliadas as experiências de organização material da vida (Zein-Elabdin e Charusheela, 2004), independente do contexto histórico e sociocultural em que as mesmas aparecem. A narrativa do desenvolvimento - como eixo-motriz em torno do qual se entende que as economias das nações devem orbitar - tem insuflado e legitimado a subalternidade, não só por constituir a base para os conceitos usualmente aceites de pobreza e riqueza, mas também por fundamentar políticas públicas nacionais e multilaterais voltadas para o combate à pobreza (ibidem). $\mathrm{O}$ desenvolvimento pode, assim, ser entendido 
como uma categoria moderna que fomenta, a partir de uma universalidade fictícia e fabricada, uma desigualdade que não se esgota, servindo para manter as linhas abissais (Santos, 2007b) que separam os que estão deste lado da linha (como "desenvolvidos" que são) dos que estão do outro lado da linha (como povos subalternizados que usualmente partilham o passado de ex-colónias).

Embora seja importante ter em conta que não há um Ocidente homogéneo e nem tão-pouco um Sul global uniforme, a modernidade - alimentada por este discurso do desenvolvimento económico -, construiu a primazia ontológica do Ocidente (Zein-Elabdin e Charusheela, 2004; Feyerabend, 1987; Meneses, 2010), colocando todos os outros povos na condição passiva de recetores de um imaginário que não produziram. Assim, povos que mantiveram lógicas peculiares de organização da vida material, a exemplo dos povos indígenas, foram encapsulados na ardilosa ideia de "tradição" - congelados num passado imóvel, socialmente destituídos do direito à dinâmica de sua cultura e para sempre presos numa dimensão a-histórica (Mohanty, 1986; Spivak, 1999; Meneses, 2010). A provincialização da Europa e do Ocidente - que Dipesh Chrakrabarty (2007) toma como uma tarefa necessária - permite, entretanto, desfazer estas e outras armadilhas epistemológicas, seja "situando" os saberes e a racionalidade moderna, seja desvelando a ficção do desenvolvimento como ideia universal.

Dentre os conhecimentos que ajudaram a consolidar um imaginário moderno, a Economia desempenhou um papel importante. Retirando dela tudo aquilo que não fosse calculável - e, portanto, tudo o que permitia entrever os processos sociais e históricos que deram vida às suas categorias - a Economia ajudou a produzir lacunas de sentido em nome da cientificidade dos seus argumentos. Ulla Grapard (2004), Antonio Callari (2004) e Zein-Elabdin (2004), com as suas leituras pós-coloniais da Economia, têm assinalado os efeitos desta aposta, uma vez que o não-económico - como dimensão que ajudou a constituir o económico como tal - desaparece do campo de visão. A supressão deste não-económico em nome da matematização da Economia, como mostra Zein-Elabdin (2004), omite as perspetivas históricas, culturais e epistemológicas a partir das quais a modernidade tem construído uma leitura acerca do Outro, o não-moderno. Neste sentido, apenas um olhar pós-colonial da Economia permitirá descortinar estas pretensas "verdades" disseminadas sobre os grupos subalternos. Constatar a multiplicidade de lógicas económicas que coexistem hoje e pôr à prova a universalidade de algumas das teorias-chave que suportam o funcionamento dos mercados - tais como as teorias da escolha racional, do valor e da escassez - são boas formas de confrontar, historicamente, aquilo que poderíamos chamar de colonialidade económica. 
Para entender, entretanto, o conceito de colonialidade económica, é preciso resgatar o sentido do próprio termo 'colonialidade'. Na condição de poder que, após o término da colonização política, se mantém ativo através de um conjunto de saberes, a colonialidade configura-se como repetição de padrões de dominação e como condição de subalternidade internalizada. Neste sentido, Quijano (1992b, 2000a, 2000b), ao falar da colonialidade do poder, lembra-nos que ela implica um padrão cognitivo a partir do qual a situação de inferioridade é construída e assimilada, sendo a "raça" (no pensamento decolonial) o argumento-chave para a classificação social e a perpetuação das relações de dominação. À colonialidade do poder corresponde, portanto, um ponto de partida, uma base que a sustenta: a colonização do imaginário (Quijano, 1992a: 438), que despreza outras lógicas de organização da vida material. A colonialidade económica é, assim, este mecanismo mediante o qual se naturalizam formas de perpetuar a desigualdade, seja pela aposta continuada nos modos de produção e consumo capitalistas, seja pela invisibilidade da pluralidade de lógicas económicas que, como ressaltam Gibson-Graham (2002), podem dar origem a diferentes formas de produzir, remunerar o trabalho e distribuir excedentes.

Aquilo que chamo, aqui, de colonialidade económica ${ }^{4}$ diz respeito, portanto, a quatro dimensões da constituição da Economia como campo de saber: 1) ao apagamento histórico das construções simbólicas que deram origem às teorias e às interpretações correntes acerca do comportamento dos agentes económicos, a exemplo de análises orientalistas desenvolvidas sob a égide do argumento da cientificidade; 2) à manutenção de estruturas cognitivas, mesmo quando já findo o colonialismo político, que mantém o imaginário subalterno preso à ficção moderna do desenvolvimento como única forma de organização material da vida; 3 ) ao fundamento técnico para programas de cooperação e financiamento multilateral nos países subalternos, tendo por lógica orientadora a adoção de parâmetros eurocêntricos de pobreza e riqueza e a manutenção de um modelo evolutivo de avaliação das práticas económicas; 4) ao fundamento epistémico que conforma uma aposta redutora e eurocêntrica na reprodutibilidade dos fenómenos perante a ideia de escala.

Se estas quatro dimensões podem ser verificadas nos países que se configuram como ex-colónias, nas diásporas das populações subalternas e nos

\footnotetext{
${ }^{4}$ Desenho esta categoria com base, principalmente, nas análises de autores que propõem uma releitura pós-colonial da Economia. De entre eles destaco Eiman Zein-Elabdin (2004), Charusheela (2004), Callari (2004), Grapard (2004) e Graubart (2004). Também me ajudam a pensar os termos desta colonialidade económica os seguintes autores: Santos (2004, 2007a, 2007b, 2014), Quijano (1992a, 2000a) e Chakrabarty (2007). Relativamente ao termo colonialidade, tomo-o emprestado do pensamento decolonial, que assim enfatiza a continuidade das relações de poder, para além do colonialismo político.
} 
grupos socialmente discriminados tanto no Sul como no Norte globais, elas fazem-se sentir de forma mais explícita no caso das mulheres. É a elas que se têm destinado ultimamente muitos dos projetos de ajuda internacional ao desenvolvimento, sobretudo nos países do Sul global. E a partir de guidelines específicas, políticas públicas e fundos comunitários norteiam a vida destas mulheres com base em condicionalidades que regulam os seus corpos e as orientam para o enquadramento de um projeto liberal da modernidade.

\section{As mulheres subalternas não são todas iguais: mulheres do Sul, inter- seccionalidade e diferentes dinâmicas da colonialidade económica}

No âmbito desta colonialidade económica, a questão de género está profundamente imbricada, já que o discurso dominante de género define lugares, deslocações possíveis e perspetivas de mudança social para mulheres e homens. A construção imagética da chamada 'mulher do Terceiro Mundo', profundamente redutora e bastante evocada na narrativa do desenvolvimento, é um caso exemplar de como a colonialidade económica se alimenta destes discursos sobre o Outro. Aqui soa bastante útil a advertência de Zein-Elabdin (1996) que assinala o risco de desconsiderarmos as posições relativas que homens e mulheres adotam - em diferentes contextos sociais, culturais e históricos - no que respeita à economia.

Spivak (1988) lembrará também que há uma heterogeneidade do subalterno, significando que existe, portanto, uma pluralidade de lugares e modos de enunciação (ou de silêncio). A colonialidade económica, na contramão desta evidência, beneficia exatamente da ficção moderna de uma homogeneidade do subalterno. Considerando que, como sinaliza Pelúcio (2012), as categorias não existem nos lugares operando necessariamente sobre os mesmos referentes, é de se ressaltar que é exatamente desta confusão epistemológica que a colonialidade económica se alimenta. Seja quando a mulher indígena, negra ou muçulmana é assumida como categoria homogénea que o discurso feminista eurocêntrico e hegemónico vem resgatar, seja quando, de forma subtil, se constrói uma análise económica menos redutora, porém ainda desconectada de um olhar necessariamente situado. A este respeito, Ochy Curiel (2005) recorda-nos que as identidades devem ser vistas como construções flutuantes e processuais e não como uma aposta na autenticidade e no universalismo de categorias, sob pena de incorrermos em binarismos e estereótipos.

Assim, discutir a colonialidade económica - e a forma múltipla como ela se materializa nos corpos das diferentes mulheres (periféricas, negras, indígenas, quilombolas, ribeirinhas) - requer falar, também, da colonialidade de género (Lugones, 2008). Ou daquilo que Lugones, mostrando as lacunas do próprio pensamento decolonial, tem chamado de 'sistema moderno-colonial de género'. 
O conceito de género, da forma como usualmente o discutimos, assume, de acordo com Lugones (2007: 168; tradução minha), uma perspetiva colonial, já que diz respeito a "um modo particular de organização das relações de produção, das relações de propriedade, das cosmologias e das formas de saber”. Isto quer dizer que a perspetiva moderno-ocidental de género não dá conta de todas as formas de construção social do termo.

Como Lugones (2008) irá observar, há aqui um processo de retroalimentação: o conceito de género constitui-se no contexto da colonialidade do poder e, simultaneamente, compõe a própria configuração desta colonialidade. Contudo, discordando de Quijano, que entende a raça como o elemento-chave de uma construção imagética eurocêntrica, Lugones afirma o género como outro eixo fundamental, de que a colonialidade do poder não dá conta integralmente. Para evidenciar que a opressão não pode ser interpretada de uma só forma e demonstrar como o sistema moderno-colonial de género introduziu novas práticas de poder que não eram intrínsecas a algumas sociedades, Lugones (2008) lembra várias comunidades nativas matriarcais, como os cherokees, em que a construção de género seguia outra lógica.

Lugones, a partir de Paula Gunn Allen, diz sobre as mulheres Cherokee:

[...] tinham tido o poder de declarar guerra, de decidir o destino dos prisioneiros, de falar ao conselho dos homens, tinham direito a serem incluídas nas decisões de política pública, de escolher se iriam casar e com quem, de pegar em armas [...] As mulheres Cherokee perderam todos estes poderes e direitos à medida que os Cherokees foram destituídos e arranjos patriarcais foram introduzidos. (2008: 11, tradução minha)

É possível perceber, com este exemplo, como a experiência das mulheres pode variar. Ressalto, portanto, a necessidade de uma análise e de um olhar situados para um entendimento menos redutor da vida das mulheres num dado contexto. Esta perspetiva permite identificar as relações de força subjacentes aos papéis de género numa dada comunidade/grupo social e diferenciá-las de outras relações de subordinação configuradas a partir de um imaginário moderno-colonial. A análise situada possibilita, ainda, destrinçar os modos de esta colonialidade económica suscitar uma narrativa e uma experiência de género com materialidade no sustento destas mulheres. Seja na luta contra os efeitos de um modelo de produção e consumo que as exclui, seja na organização de formas próprias de produzir, reunir e distribuir os recursos, as diferentes mulheres subalternas - indígenas, periféricas, negras, transgénero - vivem dilemas muito próprios, sendo importante tê-los em conta para não incorrer em análises enviesadas, que as aproximem ou separem equivocadamente. 
O modo como a opressão de género ocorre com cada uma destas mulheres em particular dependerá da sobreposição de diferentes níveis e contextos de desigualdade. Uma liderança indígena negra que viva na cidade enfrentará dilemas que provavelmente serão diferentes daqueles vividos por uma mulher indígena lésbica que viva na aldeia. Uma estudante negra e jovem que viva na periferia terá diferentes questões a enfrentar relativamente a uma mulher mestiça periférica semianalfabeta e de meia-idade. Uma mulher transgénero que viva na rua enfrentará dilemas diferentes dos vividos por uma mulher negra a quem ações afirmativas ${ }^{5}$ tenham permitido aceder a mais direitos. A realidade demonstra que a desigualdade se abate diferentemente sobre os corpos. Neste sentido, a forma como estas mulheres vão lidar com a violência de um imaginário económico que as exclui à partida não será a mesma. Da mesma maneira, o modo como tais mulheres se vão articular e criar estratégias para confrontar relações desiguais dentro e fora de suas comunidades será igualmente diverso, dadas as múltiplas posições que estas mulheres podem assumir. A hermenêutica da suspeita (Santos, 2009), pondo em xeque conceitos universalizados de que a academia usualmente parte como género, família, economia e desenvolvimento, para citar alguns - pode, aqui, ser de grande valor para uma compreensão mais alargada acerca da vida destas mulheres e das possibilidades de articulação entre elas.

A interseccionalidade (Creenshaw, 1991; Brah e Phoenix, 2004; Yuval-Davis, 1997), como perspetiva de análise, põe a nu a dinâmica perversa de interação entre múltiplas formas de produção da desigualdade. Referido primeiramente por Kimberlé Creenshaw (1991), o conceito buscou evocar a experiência simultânea de racismo e machismo vivida pelas mulheres negras - em geral subestimada tanto pelas lutas feministas como antirracistas. Hoje, orientando o olhar para a análise dos padrões de interação entre género, raça e classe em diferentes contextos - entre outras questões, como sexualidade, grupo etário e etnia -, a interseccionalidade tem-se apresentado como uma forma mais precisa de analisar o modo como as desigualdades se materializam nos corpos dos sujeitos. Neste sentido, Brah e Phoenix explicam o conceito de interseccionalidade, entendendo-o como um conjunto complexo de efeitos sobre a vida social dos indivíduos sempre que "múltiplos eixos de diferenciação - económico, político, cultural, psíquico, subjetivo e experiencial intersectam contextos historicamente específicos" (2004: 76, tradução minha). Esta definição permite-nos entender a colonialidade

\footnotetext{
5 Por ações afirmativas entende-se um conjunto de políticas públicas voltadas para reduzir a assimetria social e económica vivida por grupos histórica e socialmente discriminados, a saber: as mulheres, a população afrodescendente, os imigrantes, as comunidades indígenas e quilombolas, a população LGBT, para citar alguns exemplos.
} 
económica de uma forma mais sistémica e estrutural, tendo em conta todos os elementos que se articulam no seu âmago. Ou seja, com base na interseccionalidade, é possível identificar diferentes mecanismos hierarquizantes (de raça, etnia, classe, sexualidade) atuando conjuntamente sobre pessoas e grupos e acumulando-se, nos corpos subalternos, como formas veladas ou explícitas de violência e silenciamento.

Em face do exposto até aqui, argumento que a colonialidade económica, aguçada pelo modo interseccional de se fazer sentir na vida e nos corpos das pessoas, interliga questões de género, raça/etnia, sexualidade e classe no âmbito dos diferentes campos de saber, constituindo, assim, a liga epistemológica necessária para a sua permanente reconstituição e reprodução. Saber, poder e discurso articulam-se, assim, em torno do que eu chamaria de dinâmica interseccional das hierarquias naturalizadas, sendo a colonialidade económica uma das forças desta engrenagem - em que sexismo, racismo e hierarquia social se legitimam e fortalecem mutuamente.

Foi Boaventura de Sousa Santos (2006, 2007a) quem nos chamou a atenção para a naturalização de uma hierarquia entre diferenças - de classe, de género, etc. Argumento, a partir desta forma de monocultura - a que ele também chama de lógica de classificação social (2002) -, que é pertinente adicionar-lhe a perspetiva interseccional. Isto tendo em conta que as diferenças de género, étnicas, sexuais e de classe não são hierarquizadas em separado, mas num processo mútuo de retroalimentação. Assim, chamo a atenção para a relevância de observarmos esta engrenagem em movimento.

$\mathrm{Na}$ próxima secção, analiso o modo como a perceção desta dinâmica de hierarquias que conforma a colonialidade económica pode ser útil para uma releitura e um aprofundamento das economias feministas. Para tanto, procuro analisar de que modo o repertório pós-colonial pode ser útil para uma problematização das conexões que articulam colonialidade económica e colonialidade de género.

\section{Devem as economias feministas ser pós-coloniais?}

As economias feministas têm-se constituído como um campo relativamente vasto em termos de temáticas abordadas. Grosso modo, propõem-se analisar os papéis de género no domínio do económico, não só evidenciando as distorções que a Economia como campo de saber tem produzido relativamente às mulheres (Nelson, 2005), mas também ressaltando o facto de que o mercado não responde sozinho pela provisão das pessoas (Jennings, 1993; Thomson, 2009). Neste sentido, o trabalho não pago das mulheres no espaço da casa, com atenção ao cuidado das crianças e das pessoas idosas, constitui, por exemplo, um dos temas comuns a que a Economia usualmente 
dá pouca ou nenhuma importância. Também o modo como o mercado de trabalho amplia desigualdades por conta de formas naturalizadas de racismo em articulação com o sexismo ${ }^{6}$ constitui outro ponto que aparece na agenda das economias feministas (Saunders e Darity Jr., 2003).

Pontos de partida interessantes têm balizado o debate das economias feministas desde a publicação de Beyond Economic Man, em 1993,7 a saber: 1) que o "género [...] se refere ao modo como as sociedades atribuem 'masculidade' ou 'feminilidade' não apenas a várias pessoas, mas também a várias atividades e conceitos" (Ferber e Nelson, 2003: 1);2) que a Economia, sendo um saber criado, reflete, na verdade, as perspetivas daqueles que a constituíram como saber (ibidem), sendo, assim, apenas uma das perspetivas possíveis de análise; 3) que a economia não pode ser resumida à ideia de mercado e à máxima da escolha racional, sendo mais pertinente falarmos dela como modo de provisão (Ferber e Nelson, 2003; Jennings, 1993; Thomson, 2009) e 4) que a Economia não pode sustentar-se na precedência dada aos atributos culturalmente pensados como masculinos (Ferber e Nelson, 2003; Thomson, 2009). Todos estes pontos sublinham o necessário questionamento dos mecanismos de associação com base no género - que sugerem, dentro e fora da Economia, aquilo que é expectável relativamente a homens e mulheres -, e também sinalizam a urgente tarefa de combater a contínua desvalorização do trabalho das mulheres, onde quer que ele seja feito.

Com a consolidação de um campo de estudos a partir da década de 90, a Economia Feminista diversifica as suas temáticas, debruçando-se sobre questões epistemológicas e metodológicas que interpelam fortemente a Economia, sobretudo a neoclássica e a marxista (Nelson, 2005; Olmsted, 2004). Numa importante observação do período de constituição deste campo, Nelson (2005) faz um apanhado das transformações que o tema das economias feministas sofre. De acordo com o seu relato, ampliam-se

\footnotetext{
${ }^{6}$ Saunders e Darity Jr. (2003: 103) observam como a Economia Neoclássica aborda as desigualdades no mercado de trabalho relativamente à questão racial. Entre as explicações precariamente oferecidas pelos economistas neoclássicos estão a imperfeição do funcionamento do mercado de trabalho, as preferências externas e a falta de informação dos empregadores sobre a qualificação dos candidatos (Saunders e Darity Jr., 2003). Ainda sobre preconceito, recentes estudos sobre diferença salarial e população transgénero mostraram que as mulheres trans passam a receber salários menores depois da transição, o que não é observado no caso dos homens trans (Schilt e Wiswall, 2008: 4).

7 Segundo Nelson (2005), o campo das economias feministas começa a delinear-se por volta dos anos 70 e aborda a questão do mercado de trabalho e dos estudos ligados ao domicílio, questionando os encaminhamentos usuais dos economistas neoclássicos, baseados na teoria da escolha racional. Este período é marcado por trabalhos sobre segregação ocupacional e sobre as conexões entre relações hierárquicas no trabalho e no domićlio. Contudo, como lembra Julie Nelson, é na década de 90 que a Economia Feminista se irá organizar enquanto campo de pesquisa.
} 
os métodos de pesquisa e análise, sendo questionada a supremacia da econometria para a observação dos fenómenos. Investigadoras passam também a adotar correntes heterodoxas da economia para sustentar os seus argumentos, dialogando com outras perspetivas analíticas - pós-modernas, pós-coloniais, pós-estruturalistas - para a formulação dos referenciais teóricos. Em termos de temas, vários assuntos conformam o campo: da análise de políticas públicas voltadas para a equidade de género à observação das estruturas de poder que fundamentam uma economia genderizada, das bases da segregação ocupacional à diferença salarial entre homens e mulheres, do trabalho não pago à distribuição de tarefas nos domicílios e à vida pessoal das mulheres diante da dupla jornada de trabalho, primeiramente na função remunerada e, depois, no trabalho doméstico e de cuidado não remunerados (Nelson, 2005).

Contudo, apesar da complexidade que o campo das economias feministas tem adquirido ao longo do tempo, é de notar que persistem algumas lacunas na sua abordagem - seja em relação à diversidade do sujeito de pesquisa, ao modo como o género é analisado na articulação com outros fatores de desigualdade, ou ainda à crítica ao desenvolvimento que, como palavra-chave em diferentes escolas económicas, reitera um discurso moderno que sustenta uma presumida precedência dos valores ocidentais, como já apontado por Zein-Elabdin e Charusheela (2004). É verdade que podem ser identificados pontos comuns entre as economias feministas e as economias comunitárias pelo facto de ambas questionarem o mercado como locus privilegiado e definidor do que é economia. Também é verdade que é possível o estabelecimento de diálogos entre o campo da Economia Feminista e o da Economia Pós-Colonial, tendo como um dos pontos em comum a perspetiva de deslindar, na narrativa económica dominante, os discursos e práticas de poder. Ainda assim, considero importante ressaltar algumas ausências que abordagens cruzadas podem ajudar a complementar.

Uma primeira ausência que tem sido trabalhada a partir do feminismo negro tem a ver com a insuficiência de certas análises relativas ao trabalho doméstico e aos modelos baseados na narrativa do poder de barganha (bargaining power) para dar conta da situação das mulheres negras periféricas. Um trabalho notável a referir é o de Cecilia Rio (2012), que constata a contínua ausência da questão racial na literatura feminista sobre trabalho doméstico e analisa como o trabalho doméstico remunerado das mulheres afro-americanas nos lares das mulheres brancas não significou emancipação; contrariamente, "o locus primário do fardo das mulheres afro-americanas tem sido o mercado de trabalho, e mais especificamente, os lares brancos" (ibidem: 674; tradução minha). 
No que refere às ausências, é de notar também que as economias feministas, com a sua agenda ainda predominantemente moderna, podem resvalar com certa facilidade para uma leitura orientalista das práticas económicas das mulheres não ocidentais, corroborando assim estereótipos e valendo-se do discurso ocidental para representar e falar em nome das mulheres subalternas (Spivak, 1988; Mohanty, 1986). Assim o demonstra Jennifer Olmsted (2004), ao analisar a perspetiva da economia feminista em dois textos que versam sobre as mulheres islâmicas. No primeiro, que consiste em uma análise comparativa dos impactos do casamento na oferta de mão de obra de mulheres judias, muçulmanas e cristãs em Israel, Olmsted (2004) mostra, empiricamente, que a abordagem quantitativa de questões envolvendo diferenças culturais pode implicar a homogeneização indevida de panoramas apenas aparentemente comparáveis, levando a análises redutoras sobre a situação das mulheres muçulmanas.

No segundo texto, Olmsted analisa a resposta de Barbara Bergmann a Gary Becker relativamente às observações por ele feitas sobre a poliginia no Sudoeste Asiático. O que Olmsted observa acuradamente é que, no afã de evidenciar as relações de poder e de dominação nos casamentos poligínicos e refutar os argumentos sobre possíveis vantagens económicas nestes arranjos matrimoniais, Bergmann incorre em um sem-número de reduções: assume, à partida, que o Islão é poligínico quando, de facto, não só "[...] a monogamia permanece a norma em sociedades que permitem a poliginia”, como também a poliginia se revela bastante rara e em declínio entre os muçulmanos (Olmsted, 2004: 169; tradução minha). As comparações entre pares de opostos (família vitoriana $v s$. harém, cristão vs. muçulmano, monogamia vs. poligamia) fazem supor que o grupo das mulheres islâmicas é um grupo homogéneo. Como se estivessem presas num tempo que não se move, numa espécie de dimensão a-histórica que opõe para sempre o Islão à modernidade -, as mulheres muçulmanas continuam a ser representadas como aquelas que, para mudar de condição, necessitam do olhar e da palavra de indignação das mulheres ocidentais. Neste aspeto, Toldy (2008: 42) alerta para uma distorção usual nas leituras ocidentais: o facto de ser "pela via do lugar atribuído às mulheres nas comunidades islâmicas que se estabelece uma ligação entre o Istã e o desrespeito pelos direitos humanos". Esta perigosa ilação, que comporta uma ideia implícita de superioridade cultural do Ocidente, e que se fundamenta numa alterização do Outro (cf. Riggins, 1997 apud Toldy, 2008), não só se presta à inserção de um discurso moderno e já conhecido de desenvolvimento - sob o qual diferentes interesses podem instalar-se - como também recusa a condição de protagonismo das próprias mulheres muçulmanas que, a seu modo, têm lutado pela igualdade de género 
em diferentes instâncias e por um conjunto de mudanças nas suas instituições. ${ }^{8}$ Nestes termos, é relevante ter em conta não só o reduzido conhecimento do Ocidente acerca das diferentes correntes do feminismo islâmico (Badran, 2008, 2009; Mernissi, 1987; Rhouni, 2008) mas também da própria articulação das mulheres por maior equidade de género, à revelia da adesão ao feminismo como discurso (Barlas, 2008). E se outras leituras da articulação das mulheres em contexto não ocidental (sobretudo o islâmico) vêm ganhando algum espaço nos debates culturais sobre o feminismo, os passos são bem mais lentos quando se trata de análises no campo das 'economias' feministas.

Isto não quer dizer que análises de cunho orientalista sejam a regra. Há trabalhos recentes, no âmbito das economias feministas, que mostram perspetivas bastante promissoras relativamente a uma abordagem anti-imperial e pós-colonial (Kongar, Olmsted e Shehabuddin, 2014; Çavadar e Yasar, 2014; Shalhoub-Kevorkian et al., 2014). Mas o risco do olhar orientalista ronda as análises económicas sempre que considerações de fundo ou perspetivas metodológicas originem uma interpretação precipitada ou redutora de processos sociais complexos, de modo a presumir-se a existência de "identidades coletivas para multidões de indivíduos que na realidade são muito diferentes uns dos outros" (Said, 2007: 25). Neste sentido, análises no âmbito das economias feministas poderiam beneficiar de um diálogo mais frequente com as epistemologias do Sul (Santos, 2014; Santos e Meneses, 2010) - sensíveis aos modos pelos quais as diferentes mulheres do Sul têm articulado, criativamente, nos diferentes lugares e segundo lógicas próprias, as provisões, os cuidados, as poupanças e a vida quotidiana. Um dos maiores contributos das epistemologias do Sul, não só para repensar a economia, mas também para repensar todas as categorias ontológicas sobre as quais a ideia de conhecimento se formou e difundiu, advém da sua capacidade de revelar a epistemologia dominante como uma "epistemologia contextual", assente na "diferença cultural do mundo

\footnotetext{
${ }^{8}$ É de ter em conta a emergência de um feminismo islâmico que, de modo diferente do feminismo ocidental, preconiza a igualdade de género a partir de uma releitura do Corão. Segundo a historiadora Margot Badran (2009), a ideia de igualdade de género, no feminismo islâmico, aparece "como algo que faz parte da noção corânica de igualdade de todos os insan (seres humanos)", constituindo uma demanda por "igualdade de género no Estado, nas instituições civis, no quotidiano". Conforme ela relata, um novo feminismo islâmico parece delinear-se nos últimos anos (2009), resultando das interseç̧ões entre perspetivas seculares e islâmicas do feminismo. Dois outros pontos merecem atenção neste debate. O primeiro diz respeito à afirmação de Badran de que o feminismo não é ocidental como usualmente se presume - "Aqueles que alegam que o feminismo é ocidental e branco não sabem a sua história e perpetuam a circulação de mitos" (2008: 25; tradução minha). O segundo diz respeito à forte crítica pós-colonial que Barlas (2008: 22) endereça ao feminismo, qualificando-o como narrativa-mestra que concentra todos os debates sobre igualdade de género. Embora haja divergências entre Badran e Barlas por conta da aposta da primeira no feminismo como uma linguagem comum, o argumento de Badran de que a igualdade de género pode ser encontrada no Qur'an dialoga com a crença de Barlas de que o "Corão é antipatriarcal” (2008: 18; tradução minha).
} 
moderno cristão ocidental e [n] a diferença política do colonialismo e capitalismo" (Santos e Meneses, 2010: 10). Neste sentido, as economias feministas, no diálogo com as epistemologias do Sul, fortalecem-se em densidade crítica e epistemológica, à medida que se abrem mais às diferentes lógicas e aos arranjos a partir dos quais, em lugares e contextos específicos, as mulheres organizam a economia. As epistemologias do Sul trazem também a possibilidade de uma hermenêutica diatópica' (Santos, 2006), permitindo, via tradução intercultural (Santos, 2010), a aproximação entre "diferentes concepções de vida produtiva" (Santos, 2006: 115), entre diferentes conceitos de dignidade humana ou, ainda, entre diferentes formas de pensar igualdade de género. ${ }^{10}$

A desconstrução de certas categorias e conceitos económicos pode revelar-se igualmente útil no campo das economias feministas, sobretudo para análise da situação dos sujeitos pós-coloniais, ainda pouco representados na literatura do campo. Apesar da urgência de uma maior representatividade desta perspetiva na literatura feminista, nomeadamente no que refere à economia, há exemplos de desconstrução de conceitos e ideias universalmente aceites a partir da reflexão sobre a organização material das mulheres do Sul (Castillo, 2009; Cunha, 2011; Hillenkamp e Bessis, 2012; Lucas dos Santos, 2016).

Ao descortinar a história por trás dos conceitos e categorias, é possível detectar invisibilidades sociohistóricas não só dos sujeitos, mas também das suas práticas de resistência. É neste sentido, aliás, que Zein-Elabdin e Charusheela (2004) apontam para a urgência da construção de uma história subalterna da modernidade económica. Considerando o que disse Lugones (2007: 186) - sobre o género poder constituir-se, ele mesmo, como um conceito colonial, definidor de um modo particular de organização das relações de produção, de propriedade e de constituição do saber -, argumento que um diálogo mais efetivo entre as economias feministas e as economias pós-coloniais pode revelar-se frutífero. Uma economia feminista pós-colonial pode conferir visibilidade e historicidade àquelas estratégias de resistência das mulheres subalternas que, escapando às formas protocolares de insurgência, questionam e ampliam o domínio do político ${ }^{11}$ e confrontam a

\footnotetext{
9 A hermenêutica diatópica, segundo Santos (2006: 115), "consiste no trabalho de interpretação entre duas ou mais culturas com vista a identificar preocupações isomórficas entre elas e as diferentes respostas que fornecem para elas".

${ }_{10}$ A respeito das diferentes formas de se pensar igualdade de género para além do discurso secular do feminismo, ver Barlas (2008), que convida a uma outra leitura do Qur'an relativamente à equidade entre homens e mulheres. Sobre o conceito de dignidade humana para além da perspetiva ocidental dos direitos humanos - a exemplo do conceito islâmico de umma e da concepção hindu de dharma - ver Santos (2006, 2009).

${ }^{11}$ Para uma análise de como os Estudos Subalternos esgarçam o domínio do político, propondo uma historiografia subalterna da Índia, ver Góes (2013).
} 
representatividade da narrativa linear e parcial da modernidade económica. A economia feminista pós-colonial pode fazer, no domínio da Economia, aquilo que fizeram os Estudos Subalternos com a Historiografia (Guha, 1982; Góes, 2013).

O questionamento à modernidade, aliás, mantém-se ainda como uma das fragilidades epistemológicas atribuídas às economias feministas, no seu panorama geral. Se é verdade que algumas pesquisadoras - como Lourdes Benería, Julie Nelson e Gillian Hewitson - têm dirigido críticas à perspetiva moderna da economia mainstream (apud Charusheela e Zein-Elabdin, 2003),,$^{12}$ e que algumas chegam mesmo a introduzir uma crítica simultaneamente feminista e pós-colonial ao desenvolvimento (veja-se, por exemplo, Kongar, Olmsted and Shehabuddin, 2014), não devemos perder de vista que "muito da perspetiva feminista ligada ao desenvolvimento permanece intransigentemente modernista" (Charusheela e Zein-Elabdin, 2003: 176, tradução minha), apesar das leituras heterodoxas da Economia que também promovem. Do mesmo modo, a crítica ao desenvolvimento parece estar no cerne das tensões ainda existentes entre as economias feministas e pós-coloniais, tendo em conta que nem todas as análises feministas sobre a Economia estão de acordo quanto a ponderar as desigualdades de género como um efeito não só de relações patriarcais, mas também do discurso do desenvolvimento. Este é um ponto central na crítica de Zein-Elabdin e Charusheela, que ora dirigem à Economia, nas suas diferentes correntes, ora endereçam especificamente à Economia Feminista:

A questão do desenvolvimento é central no relacionamento entre os feminismos ocidentais e pós-coloniais. Ao desconstruir a categoria de mulher do Terceiro Mundo, Chandra Mohanty (1986) ressaltou o problema da representação do Outro no feminismo ocidental. A academia feminista tem geralmente tomado como certa a noção de desenvolvimento para as mulheres do Terceiro Mundo, como evidenciado pela indústria massiva de mulher-e-desenvolvimento, agora reformulado como género-e-desenvolvimento (GAD) - com seus projetos extensivos, literatura, especialistas e programas de treinamento. (Charusheela and Zein-Elabdin, 2003: 183; tradução minha)

\footnotetext{
${ }^{12}$ Zein-Elabdin e Charusheela, como académicas que têm liderado a construção de um projeto de crítica pós-colonial da Economia, fazem uma análise detalhada dos contributos e lacunas tanto da economia heterodoxa como da economia feminista. Evidenciam que diferentes correntes económicas, para além da neoclássica, têm caído na mesma armadilha epistemológica, quando se trata de analisar o mundo pós-colonial: o orientalismo e o desenvolvimentalismo. Relativamente às economias feministas, as autoras fazem uma análise minuciosa das tensões que ainda se mantêm entre estas e as economias pós-coloniais, apresentando os primeiros passos para a proposição de uma economia feminista pós-colonial. Ver, a este respeito, Charusheela e Zein-Elabdin (2003) e Zein-Elabdin e Charusheela (2004).
} 
Com esta crítica, Charusheela e Zein-Elabdin contribuem para delinear, em termos conceituais, os contornos de uma Economia Pós-Colonial e, de forma mais específica, o de uma economia pós-colonial feminista, pontuando que esta última deve "interrog[ar] o orientalismo e o desenvolvimentalismo do discurso económico e contribu[ir] para a criação de enquadramentos alternativos" (2003: 184). Restam, entretanto, muitas perguntas: que cuidados epistemológicos e metodológicos se revelam úteis para desarmar a colonialidade económica e da colonialidade de género relativamente às mulheres subalternas? Como garantir que as economias do Sul, protagonizadas por diferentes mulheres - indígenas, quilombolas, periféricas -, sejam reconhecidas como formas económicas contemporâneas com racionalidades específicas, quando até as Economias Pós-colonial e Feminista não lhes têm dado a devida atenção? Como pôr em diálogo as teorias feministas com uma perspetiva de ecologia das produtividades (Santos, 2006, 2007a)?

Importa referir que o conceito de Economias do Sul que aqui proponho não tem um sentido geográfico mas sim sociológico, estando em diálogo estreito com o conceito de epistemologias do Sul (Santos, 2010, 2014), que tem como ideia central nomeadamente que "a compreensão do mundo é muito mais ampla do que a compreensão ocidental do mundo" (Santos, 2010: 41-42; tradução minha). Por economias do Sul entendo, portanto, modos não capitalistas de organizar a vida material no âmbito do Sul global (estejamos falando do Sul que está no Sul ou do Sul invisível que também está no Norte) e que, constituindo diferentes racionalidades, escapam à perspetiva da distinção social que marca a dinâmica das sociedades mercantis. Constituem estas economias modos não capitalistas de produzir, consumir, poupar e trocar que não se encaixam na narrativa económica dominante e nem podem por ela ser explicadas. Eminentemente populares, as economias do Sul, embora usualmente consideradas irrelevantes e sem escala pelo discurso da Economia, impõem-lhe desafios epistemológicos e outros parâmetros de valoração. Nas economias do Sul, os ritmos, os modos de fazer e os saberes das pessoas não têm por finalidade responder às expetativas do mercado. Além disso, os princípios económicos de redistribuição, reciprocidade e 'domesticidade' estão bem mais evidentes nestes arranjos. Neles, a provisão é, de facto, a preocupação central e as mulheres têm o protagonismo. É de referir também que estes modos mais coletivos de pensar e cuidar da provisão trazem à superfície diferentes racionalidades estéticas, dinâmicas de produção e sociabilidades, chamando a atenção para a importância dos aspetos não económicos subjacentes ao domínio do económico.

Neste contexto, conceitos como os de tradução intercultural, cosmopolitismo subalterno e ecologia das temporalidades, propostos por Boaventura 
de Sousa Santos, revelam-se aqui importantes não só para trazer à cena as múltiplas racionalidades inerentes a estas economias do Sul, como também para evidenciar o potencial de luta e de diálogo entre diferentes mulheres na conformação e 'afirmação' destas outras lógicas de organização da vida material. Neste sentido, os chamados feminismos do Sul, em sintonia com uma ecologia de produtividades, propiciam um inestimável alargamento epistemológico da economia, na medida que: 1) recusam o viés eurocêntrico que as teorias económicas podem assumir; 2) chamam a atenção para os contributos das mulheres do Sul na transformação do doméstico em campo político de luta (Lucas dos Santos, 2016);3) têm a capacidade de aprofundar o debate sobre o trabalho doméstico e de cuidado, ao problematizar assimetrias de classe e étnico-raciais, trazendo, assim, diferentes perspetivas para este debate; 4) trazem para a cena pública a produção doméstica das mulheres, constituindo espaços de articulação e de autonomia simbólica e material; 5) enfatizam o lugar fundamental das mulheres na conformação dos mecanismos de reciprocidade e redistribuição das Economias do Sul.

\section{Pensando a partir do Sul para um alargamento epistemológico da Economia e da Economia Feminista: considerações finais}

Pode dizer-se que as economias feministas do Sul se articulam em três direções. Primeiramente, devem comprometer-se com uma arqueologia da subalternidade, identificando lacunas e vieses que podem atravessar, nas diferentes teorias económicas, as análises sobre as mulheres do Sul global. Assim, preocupam-se em observar a insuficiência, a imprecisão e a colonialidade do conceito de desenvolvimento em diferentes contextos, onde o discurso económico planta a construção de guidelines para a inserção económica e social de mulheres periféricas e/ou provenientes de outros grupos minoritários ${ }^{13}$ (mulheres islâmicas, indígenas, ciganas, afrodescendentes, imigrantes, transgénero). Cumpre indagar: que relação podemos

\footnotetext{
${ }_{13}$ Ressalto a relevância do trabalho de Zein-Elabdin e Charusheela para escrever este artigo e para pensar o que chamo aqui de Economias Feministas do Sul. Optei por não fechar o texto em torno do conceito de "economias feministas pós-coloniais", embora o mencione algumas vezes, por dois motivos: pelo diálogo mais profundo com as epistemologias do Sul e por considerar que o domínio do pós-colonial não se aplica tanto às realidades da América Latina, que são as que mais frequentemente cito neste texto. Isto não significa que não considere as perspetivas pós-coloniais de suma importância para uma reflexão sobre as economias subalternas. Apenas entendo que o conceito de Economias do Sul evidencia uma atenção mais explícita às diferentes lógicas de organização da vida material, vendo como contemporâneas aquelas economias que antes só interessavam ao campo da Antropologia Económica. Entendo, também, que o termo Economias Feministas do Sul não só ressalta o caráter múltiplo destes diferentes modos de provisão, como também traz à superfície o protagonismo das mulheres do Sul no que refere aos princípios da reciprocidade e da redistribuição, usualmente subvalorizados nas análises económicas, mesmo as feministas.
} 
estabelecer entre as políticas públicas desenhadas a partir do conceito ocidental de desenvolvimento e a perpetuação de uma situação de pobreza diretamente relacionada com desigualdades étnico-raciais e de classe? De que modo a luta contra a pobreza através de programas de 'empoderamento' de mulheres obstaculiza a perceção do discurso neocolonial e a reedição que ele faz de relações económicas desiguais? Estas e outras questões evidenciam o oportuno alargamento de horizonte nas análises económicas feministas.

Em segundo lugar, as economias feministas do Sul enfatizam uma abordagem interseccional - que já aparece tanto nas economias feministas como numa perspetiva pós-colonial da Economia. Há aqui, entretanto, um detalhe importante que merece atenção: para maior acuidade epistemológica na análise do impacto da Economia na vida das mulheres subalternas é preciso ter em conta o modo 'como' as diferenças fazem diferença e se articulam para um contexto de desigualdade socioeconómica ou mesmo de privilégio (Yuval-Davis, 2011). Argumento, portanto, que é necessário ter atenção a uma dinâmica interseccional das hierarquias naturalizadas, de modo a que se identifique, com maior precisão, as engrenagens, sempre moventes, que entrelaçam subalternidade económica, sexismo, racismo e hierarquia social.

Cabe às economias feministas do Sul, portanto, a tarefa de: 1) mapear as diferentes hierarquias que se abatem sobre as mulheres num determinado contexto, tendo em conta, nas análises comparadas, a própria trajetória do conceito de género e dos modos de resistências das mulheres; 2) verificar como estas hierarquias se combinam para compor o tecido simbólico em que se vão materializar os discursos de dominação e de insurgência; 3) analisar as dinâmicas de poder acionadas por estas 'composições contextuais', identificando os elementos que acionam e alimentam a colonialidade de género; 4) incluir este dado da colonialidade de género nas usuais análises comparadas feitas no campo da Economia.

Por fim, é de supor que as economias feministas do Sul abram um espaço mais alargado para a análise das múltiplas formas de organização da vida material, bem como da dimensão política e da autonomia simbólica a partir dela. Trazem, assim, um importante contributo: o de observar diferentes lógicas de produção e de distribuição dos excedentes - que escapam ao modo de funcionamento dos mercados, como já apontado por GibsonGraham (2002) - e o de ressaltar o protagonismo das mulheres na conformação da reciprocidade e da redistribuição em suas economias, indo além do usual e não menos relevante debate sobre o domínio do doméstico e a participação das mulheres no mercado formal de trabalho. 


\section{Referências bibliográficas}

Badran, Margot (2008), "Engaging Islamic Feminism”, in Annita Kynsilehto (org.), Islamic Feminism: Current Perspectives. Finland: University of Tampere, 25-36.

Badran, Margot (2009), Feminism in Islam: Secular and Religious Convergences. London: Oneworld Publications.

Barlas, Asma (2008), "Engaging Islamic Feminism: Provincializing Feminism as a Master Narrative”, in Annita Kynsilehto (org.), Islamic Feminism: Current Perspectives. Finland: University of Tampere, 15-24.

Bhambra, Gurminder (2014), "Postcolonial and Decolonial Dialogues", Postcolonial Studies, 17(2), 115-121.

Brah, Avtar (2006), "Diferença, diversidade, diferenciação", Cadernos Pagu, 26, 329-376. Brah, Avtar; Phoenix, Ann (2004), "Ain't I A Woman? Revisiting Intersectionality", Journal of International Women's Studies, 5(3), 75-86.

Caldas, José Castro (2010), "Economia e crematística dois mil anos depois", in Vítor Neves; José Castro Caldas (orgs.), A economia sem muros. Coimbra: CES/Almedina, 45-57.

Callari, Antonio (2004), "Economics and the Postcolonial Other", in Eiman ZeinElabdin; S. Charusheela (orgs.), Postcolonialism Meets Economics. London: Routledge, 113-129.

Castillo, Aída (2009), Feminismos poscoloniales: reflexiones desde el sur del Río Bravo, in Liliana Suárez Navaz; Rosalva Aída Hernández Castillo (orgs.), Descolonizando el feminismo: teorías y prácticas desde los márgenes. Valencia: Editorial Cátedra, 75-116. Çavadar, Gamze; Yasar, Yavus (2014), "Moving beyond Culturalism and Formalism: Islam, Women, and Political Unrest in the Middle East", Feminist Economics, 20(4), 33-57.

Chakrabarty, Dipesh (2007), "Introduction: The Idea of Provincializing Europe", in Provincializing Europe. New Jersey: Princeton University Press, 3-23.

Charusheela, S. (2004), "Postcolonial Thought, Postmodernism, and Economics: Questions of Ontology and Ethics”, in Eiman Zein-Elabdin; S. Charusheela (orgs.), Postcolonialism Meets Economics. London: Routledge, 40-58.

Charusheela, S.; Eiman Zein-Elabdin (2003), "Feminism, Postcolonial Thought and Economics", in Marianne Ferber; Julie Nelson (orgs.), Feminist Economics Today: Beyond Economic Man. Chicago: University of Chicago Press, 175-192.

Creenshaw, Kimberlé (1991), "Mapping the Margins: Intersectionality, Identity Politics, and Violence against Women of Color", Stanford Law Review, 43(6), 1241-1299.

Cunha, Teresa (2011), "A arte de xiticar num mundo de circunstâncias ainda não ideais. Feminismo e descolonização das teorias económicas contemporâneas", in Teresa Cunha (org.), Ensaios pela democracia. Justiça, dignidade e bem-viver. Porto: Afrontamento, 73-97.

Curiel, Ochy (2005), "Identidades esencialistas o construcción de identidades políticas: el dilema de las feministas afrodescendientes”, in Mujeres desencadenantes. Los 
Estudios de Género en la República Dominicana al inicio del tercer Milenio. INTEC. Consultado a 19.06.2017, em http://webcache.googleusercontent.com/search?q=cach e:BnKmqwWZLoIJ:interamericanos.itam.mx/documentos/Identidades_esencialistas. $\mathrm{doc}+\& \mathrm{~cd}=1 \& \mathrm{hl}=\mathrm{pt}-\mathrm{PT} \& \mathrm{ct}=\mathrm{clnk} \& \mathrm{gl}=\mathrm{pt} \& \mathrm{client}=$ safari.

Danby, Collin (2004), "Contested States, Transnational Subjects: Toward a Post Keynesianism without Modernity”, in Eiman Zein-Elabdin; S. Charusheela (orgs.), Postcolonialism Meets Economics. London: Routledge, 253-270.

Ferber, Marianne; Nelson, Julie (orgs.) (2003), Feminist Economics Today: Beyond Economic Man. Chicago: University of Chicago Press.

Feyerabend, Paul (1987), Farewell to Reason. London: Verso.

Gibson-Graham, J. K. (2002), “A Diverse Economy: Rethinking Economy and Economic Representation”. Consultado a 19.06.2017, em http://cscs.res.in/dataarchive/textfiles/ textfile.2007-11-30.8168238051/file.

Góes, Camila Massaro de (2013), "De Antonio Gramsci aos Subaltern Studies: notas sobre a noção de subalternidade”. Consultado a 19.06.2017, em http://www. conferencias.fflch.usp.br/sdpscp/IIIsem/paper/view/24/24.

Gramsci, Antonio (1971), Selections from the Prison Notebooks. New York: International Publishers.

Grapard, Ulla (2004), “Trading Bodies, Trade in Bodies: The 1878 Paris World Exhibition as Economic Discourse”, in Eiman Zein-Elabdin; S. Charusheela (orgs.), Postcolonialism Meets Economics, Postcolonialism Meets Economics. London: Routledge, 91-112.

Graubart, Karen (2004), "Hybrid Thinking: Bringing Postcolonial Theory to Colonial Latin American Economic History”, in Eiman Zein-Elabdin; S. Charusheela (orgs.), Postcolonialism Meets Economics. London: Routledge, 215-234.

Guha, Ranajit (1982), Subaltern Studies I: Writings on South Asian History and Society. Delhi: Oxford University Press.

Hillenkamp, Isabelle; Bessis, Franck (2012), "L'innovation sociale par l'économie solidaire en Bolivie: une démocratisation des conventions de production et de genre", Innovations, 38(2), 85-105.

Jennings, Ann (1993), "Public or Private? Institutional Economics and Feminism", in Marianne Ferber; Julie A. Nelson (orgs.), Beyond Economic Man: Feminist Theory and Economics. Chicago: University of Chicago Press, 111-129.

Kongar, Ebru; Olmsted, Jennifer; Shehabuddin, Elora (2014), “Gender and Economics in Muslim Communities: A Critical Feminist and Postcolonial Analysis", Feminist Economics, 20(4), 1-32.

Lucas dos Santos, Luciane (2016), "Polanyi through the Lens of Epistemologies of the South and Postcolonial Feminist Economics: Different Glances at the Concept of Disembeddedness", EMES Selected Papers - 2nd Polanyi-EMES International Seminar. 
Lugones, María (2007), "Heterosexualism and the Colonial/Modern Gender System", Hypatia, 22(1), 186-209.

Lugones, María (2008), “The Coloniality of Gender”, Worlds \& Knowledges Otherwise, 2 (Spring), 1-17. Consultado a 19.06.2017, em https://globalstudies.trinity.duke.edu/ wp-content/themes/cgsh/materials/WKO/v2d2_Lugones.pdf.

Meneses, Maria Paula (2010), "Outras vozes existem, outras histórias são possíveis", in Regina Leite Garcia (org.), Diálogos cotidianos. Petrópolis: DP et Alii, 247-265.

Mernissi, Fatima (1987), Le harem politique: le prophète et les femmes. Paris: Albin Michel. Mignolo, Walter (2000), Local Histories/Global Designs. Coloniality, Subaltern Knowledges and Border Thinking. Princeton: Princeton University Press.

Mignolo, Walter; He, Weihua; Xie, Haiyan (2012), "Harmonious Prospect and Decolonial Image of the World", Marxism and Reality, 4, 110-120.

Mitchell, Timothy (2005), "The Work of Economics: How a Discipline Makes its World”, European Journal of Sociology, 46, 297-320.

Mohanty, Chandra (1986), "Under Western Eyes: Feminist Scholarship and Colonial Discourses”, Boundary 2, 12(3), 333-358.

Nelson, Julie (2005), "Feminist Economics”, in Steven N. Durlauf; Lawrence E. Blume (orgs.), The New Palgrave Dictionary of Economics. London/New York: Palgrave Macmillan. Consultado a 19.06.2017, em http://www.dictionaryofeconomics.com/ article?id=pde2008_F000286.

Olmsted, Jennifer (2004), "Orientalism and Economic Methods: (Re)Reading Feminist Economic Discussions of Islam”, in Eiman Zein-Elabdin; S. Charusheela (orgs.), Postcolonialism Meets Economics. London: Routledge, 165-182.

Pelúcio, Larissa (2012), "Subalterno quem, cara pálida? Apontamentos às margens sobre pós-colonialismos, feminismos e estudos queer”, Revista Contemporânea, 2(2), 395-418.

Quijano, Anibal (1992a), "Colonialidad y modernidad-racionalidad”, in Heraclio Bonillo (org.), Los conquistados. Bogotá: Tercer Mundo Ediciones, Flacso, 437-449.

Quijano, Anibal (1992b), “'Raza', 'etnia', 'nación’ en Mariátegui: cuestiones abiertas”, in Roland Forgues (org.), José Carlos Mariátegui y Europa. La otra cara del descubrimiento. Lima: Amauta, 167-188.

Quijano, Anibal (2000a), “Colonialidad del poder y clasificación social”, Journal of World-Systems Research, 6(2), 342-386.

Quijano, Anibal (2000b), "Coloniality of Power, Eurocentrism, and Latin America", Nepantla, 1(3), 533-580.

Rhouni, Raja (2008), "Rethinking 'Islamic Feminist Hermeneutics': The Case of Fatima Mernissi”, in Annita Kynsilehto (org.), Islamic Feminism: Current Perspectives. Finland: University of Tampere, 103-115.

Rio, Cecilia (2012), "Whiteness in Feminist Economics: The Situation of Race in Bargaining Models of the Household", Critical Sociology, 38(5), 669-685. 
Said, Edward (2007), Orientalismo: O Oriente como invenção do Ocidente. São Paulo: Companhia das Letras.

Santos, Boaventura de Sousa (2006), A gramática do tempo: para uma nova cultura política. Porto: Afrontamento.

Santos, Boaventura de Sousa (2007a), Renovar a teoria crítica e reinventar a emancipação social. São Paulo: Boitempo.

Santos, Boaventura de Sousa (2007b), "Beyond the Abyssal Thinking”, Review, 30(1), 45-89.

Santos, Boaventura de Sousa (2009), "If God Were a Human Rights Activist: Human Rights and the Challenge of Political Theologies”, Law, Social Justice \& Global Development Journal (LGD). Consultado a 02.11.2017, em https://www2.warwick. ac.uk/fac/soc/law/elj/lgd/2009_1/santos/.

Santos, Boaventura de Sousa (2010), Refundación del Estado en América Latina: perspectivas desde una epistemología del Sur. La Paz: Plural Editores.

Santos, Boaventura de Sousa (2014), Epistemologies of the South: Justice against Epistemicide. London: Paradigm Publishers.

Santos, Boaventura de Sousa; Meneses, Maria Paula (2010), Epistemologias do Sul. Coimbra: Almedina/CES [2. ${ }^{a}$ ed.].

Saunders, Lisa; Darity Jr, William (2003), "Feminist Theory and Racial Economic Inequality", in Marianne Ferber; Julie Nelson (orgs.), Feminist Economics Today: Beyond Economic Man. Chicago: University of Chicago Press, 101-114.

Schilt, Kristen; Wiswall, Matthew (2008), "Before and After: Gender Transitions, Human Capital, and Workplace Experiences”, The B.E. Journal of Economic Analysis and Policy, 8(1), 1-28.

Shalhoub-Kevorkian, Nadera; Griecci, Nina; Zubi, Himmat; Busbridge, Rachel (2014), "Funding Pain: Bedouin Women and Political Economy in the Naqab/Negev", Feminist Economics, 20(4), 374-396.

Spivak, Gayatri (1988), "Can the Subaltern Speak?", in Cary Nelson; Lawrence Grossberg (orgs.), Marxism and the Interpretation of Culture. Chicago: University of Illinois, 271-313.

Spivak, Gayatri (1999), A Critique of Postcolonial Reason: Towards a History of the Vanishing Present. Cambridge, MA: Harvard University Press.

Thomson, Emily (2009), "Do Ends Justify Means? Feminist Economics Perspectives on the Business Case for Gender Equality in the UK Labour Market”, e-cadernos ces, 5 , 118-133. Consultado a 19.06.2017, em https://eces.revues.org/298.

Toldy, Teresa (2008), "Allah in Deutschland? Representações da comunidade islâmica na Revista Der Spiegel”, Revista Comunicação, Mídia e Consumo, 5(14), 33-53.

Yuval-Davis, Nira (1997), Gender and Nation. London: Sage.

Yuval-Davis, Nira (2011), "Women, Citizenship and Difference”, Feminist Review, $57,4-27$. 
Zein-Elabdin, Eiman (1996), "Development, Gender, and the Environment: Theoretical or Contextual Link? Toward an Institutional Analysis of Gender”, Journal of Economic Issues, 30(4), 929-947.

Zein-Elabdin, Eiman (2004), "Articulating the Postcolonial (with Economics in Mind)", in Eiman Zein-Elabdin; S. Charusheela (orgs.), Postcolonialism Meets Economics. London: Routledge, 21-39.

Zein-Elabdin, Eiman; Charusheela, S. (2004), "Introduction: Economics and Postcolonial Thought”, in Eiman Zein-Elabdin; S. Charusheela (orgs.), Postcolonialism Meets Economics. London: Routledge, 1-18.

Artigo recebido a 03.08.2017

Aprovado para publicação a 25.10.2017

\section{Luciane Lucas dos Santos}

Centro de Estudos Sociais da Universidade de Coimbra

Colégio de S. Jerónimo, Largo D. Dinis, Apartado 3087, 3000-995 Coimbra, Portugal Contacto: lucianelucas@ces.uc.pt

\section{Must Feminist Economy be Post- -colonial? Economic Coloniality, Gender, and Epistemologies of the South}

In this article I analyse the phenomenon of economic coloniality, observing its impact on the social fabric and how it affects women's lives in particular - namely those in subordinate positions, either in the peripheries of the world's major cities or where they constitute minorities, or symbolically, in the global South and North. My interest is to examine how economic and gender colonialities interact, accentuating the situations of inequality in which women find themselves. Finally, I inquire into the extent that feminist economies can open up a dialogue more

\section{L'économie féministe doit-elle être} postcoloniale? Colonialité économique, genre et épistémologies du Sud

Dans cet article, je me penche sur le phénomène de la colonialité économique, en observant ses impacts sur le tissu social et la façon dont en est particulièrement atteinte la vie des femmes - notamment les subalternes, qu'elles se trouvent à la périphérie des grandes villes du monde ou qu'elles constituent des minorités numériques ou symboliques dans le Sud ou le Nord globaux. Il m'importe d'analyser comment les colonialités économiques et de genre interagissent, en accentuant la situation d'inégalité dans laquelle se trouvent ces femmes. Enfin, je cherche aussi à savoir dans quelle mesure les 
closely with post-colonial theories - in particular, post-colonial studies of economy and with epistemologies of the South as a way to explore the contradictions of the modern discourse on development. $\mathrm{I}$ argue that feminist economies can benefit from the post-colonial perspective and the epistemologies of the South to analyse the inconsistencies of the universalisation of this discourse and the intersectional dynamics which bring together the issues of gender, race/ethnicity, and class within the scope of the economy.

Keywords: economic coloniality; epistemologies of the South; Feminist Economics; gender; postcolonial studies on Economics. économies féministes peuvent parvenir à dialoguer plus étroitement avec les théories postcoloniales - en particulier les études postcoloniales de l'Économie - et avec les épistémologies du Sud, en sorte à exposer les contradictions du discours moderne de développement. J'argue que les économies féministes peuvent tirer parti de la perspective postcoloniale et des épistémologies du Sud pour analyser les inconsistances de l'universalisation de ce discours et de la dynamique intersectionnelle qui connecte des questions de genre, de race/ethnie et classe dans le domaine de l'Économie.

Mots-clés: colonialité économique; économie féministe; épistémologie du Sud; études postcoloniales de l'économie; genre. 
